\title{
Biometria testicular, eletroejaculação e características seminais de caititus, Tayassu tajacu Linnaeus, 1758 (Mammalia, Artiodactyla, Tayassuidae) mantidos em cativeiro na Amazônia Oriental
}

Priscila Reis KAHWAGE ${ }^{1}$, Alexandre Rossetto GARCIA², Diva Anelie de Araújo GUIMARÃES³, Otávio Mitio $\mathrm{OHASHI}^{4}$, Rosemar Silva LUZ-RAMOS5, Hilma Lúcia Tavares DIAS ${ }^{6}$, Natália Inagaki de ALBUQUERQUE Mário Mansour Pinheiro BARTHA ${ }^{8}$

\begin{abstract}
RESUMO
Estudos relacionados à obtenção e avaliação de sêmen de Tayassu tajacu são escassos, sendo necessárias pesquisas a respeito. Os objetivos do estudo foram avaliar a biometria testicular de caititus adultos cativos, testar a eficiência da eletroejaculação para obtenção de sêmen e avaliar suas características seminais ao longo do ano. Procedeu-se à eletroejaculação em oito animais adultos e as amostras de sêmen colhidas foram avaliadas quanto às características físicas e morfológicas. Os animais tinham

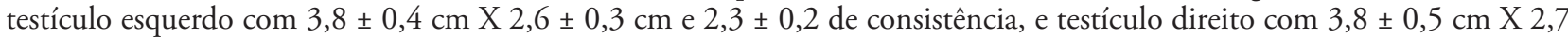
$\pm 0,3 \mathrm{~cm}$ e $2,3 \pm 0,2$ de consistência. A taxa de sucesso nas colheitas foi de $75,21 \%$. O sêmen possuiu: volume $0,81 \pm 0,86$ $\mathrm{mL}$, concentraçáo $137,44 \pm 153 \times 10^{6}$ sptz mL ${ }^{-1}, \mathrm{pH} 7,92 \pm 0,73$, motilidade $52,66 \pm 28,79 \%$, vigor 2,2 $\pm 0,8$, integridade de membrana plasmática $55,84 \pm 28,55 \%$, defeitos maiores $22,87 \pm 12,93 \%$, defeitos menores $9,11 \pm 5,88 \%$ e defeitos totais $31,52 \pm 13,81 \%$. Os animais apresentaram simetria testicular, a eletroejaculação se mostrou eficiente para a obtençáo de ejaculados em caititus e as flutuaçôes observadas na produção seminal náo foram suficientes para caracterizá-los como animais de reprodução sazonal.
\end{abstract}

PALAVRAS-CHAVE: andrologia, animais silvestres, cateto, sêmen, sazonalidade.

\section{Testicular biometry, electroejaculation and seminal features of captive collared peccaries (Tayassu tajacu Linnaeus, 1758, Artiodactyla, Tayassuidae) raised in the Eastern Amazon}

\footnotetext{
ABSTRACT peccaries as seasonal reproductive animals.

1 Universidade Federal do Pará, E-mail: priscila.kahwage@hotmail.com

2 Embrapa Amazônia Oriental, E-mail: argarcia@cpatu.embrapa.br

3 Universidade Federal do Pará, E-mail: diva@ufpa.br

${ }^{4}$ Universidade Federal do Pará, E-mail: ohashi@ufpa.br

${ }^{5}$ Universidade Federal do Pará, E-mail: roseluzes@yahoo.com.br

${ }^{6}$ Universidade Federal do Pará, E-mail: hiltav@ufpa.br

7 Embrapa Amazônia Oriental, E-mail: natalia@cpatu.embrapa.br

${ }^{8}$ Universidade Federal do Pará, E-mail: mariobartha@hotmail.com
}

Research development in semen collection and sperm evaluation of Tayassu tajacu are necessary. The aims of this research were to evaluate testicular biometry of captive collared peccaries, test electroejaculation for semen collection and evaluate seminal characteristics during the year. Eight animals were submitted to electroejaculation and semen samples were evaluated according their physical and morphological characteristics. Left testicles measured $3.8 \pm 0.4 \mathrm{~cm} \mathrm{X} 2.6 \pm 0.3 \mathrm{~cm}$ and presented $2.3 \pm 0.2$ of consistence, while right testicles were $3.8 \pm 0.5 \mathrm{~cm} \mathrm{X} 2.7 \pm 0.3 \mathrm{~cm}$ and presented $2.3 \pm 0.2$ of consistence. Success rate on semen collections achieved $75.21 \%$. Semen presented $0.81 \pm 0.86 \mathrm{~mL}$ (volume), $137.44 \pm 153 \times 10^{6} \mathrm{sptz} \mathrm{mL}^{-1}(\mathrm{sperm}$ concentration), $7.92 \pm 0.73(\mathrm{pH}), 52.66 \pm 28.79 \%$ (sperm motility), $2.2 \pm 0.8$ (vigour), $55.84 \pm 28.55 \%$ (plasmatic membrane integrity), $22.87 \pm 12.93 \%$ (primary defects), $9.11 \pm 5.88 \%$ (secondary defects) and $31.52 \pm 13.81 \%$ (overall defects). Seminal characteristics showed no expressive variation along the year. Testicular symmetry was observed, electroejaculation was an efficient method to semen collection and slight mensal oscillations of seminal quality were not enough to characterize collared

KEY WORDS: andrology, collared peccary, seasonality, semen, wild animals. 


\section{INTRODUÇÃO}

O caititu, Tayassu tajacu Linnaeus, 1758 é um mamífero silvestre, usado pelas populaçóes rurais da Amazônia como importante fonte de proteína alimentar e renda. Mas, a caça indiscriminada para abastecimento do mercado ilegal de carne e peles, associada à destruição dos habitats, têm ocasionado redução da espécie (Homma 1992; Wilson 1994; Bennett e Robinson 2000). Nas regiôes Sul e Sudeste do país, esta já é considerada criticamente ameaçada de extinção (Passamani e Mendes 2007; IAP 2009).

Diante de seu potencial comercial, o interesse pela criação de caititus em cativeiro tem sido crescente. Por isso, o desenvolvimento de modelos sustentáveis de criação pode constituir alternativa racional para aproveitar economicamente os animais cativos, favorecer a segurança alimentar de populaçôes tradicionais e contribuir para reduzir a pressão de caça.

Para a manutenção da espécie em cativeiro, seja para comercialização ou conservação, o conhecimento de sua biologia reprodutiva é primordial (Andrabi e Maxwell 2007; Mayor et al. 2007), mas poucos estudos com machos têm sido realizados (Lochmiller et al. 1985; Costa et al. 2004; Costa e Paula 2005; Costa et al. 2007). Por isso, informaçôes básicas sobre anátomo-fisiologia reprodutiva, métodos seguros para colheita de ejaculados, suas características fisiológicas e formas de conservação do sêmen devem ser investigadas.

A avaliação morfométrica dos testículos tem fundamental importância para a identificação de patologias e alteraçôes gonadais, que podem influenciar diretamente na produção e qualidade seminal, com impactos sobre a fertilidade do indivíduo (Hellgren et al. 1989; Sonner et al. 2004). Em várias espécies, a eletroejaculação tem sido apontada como método de eleição para obtenção de sêmen, dada sua segurança e eficiência quando associada aos protocolos anestésicos e de estímulos elétricos específicos para cada espécie estudada (Morato et al. 1998).

Até o presente, poucos trabalhos sobre colheita e avaliação seminal em caititus foram realizados (Lochmiller et al. 1985; Hellgren et al. 1989; Costa e Paula 2005). Embora os primeiros ensaios com uso da eletroejaculação tenham sido bem sucedidos, há necessidade de ampliação dos estudos sobre o método, principalmente tendo como foco animais mantidos em cativeiro, sob constantes medidas de manejo, na região amazônica.

Assim, os objetivos do presente trabalho foram: (i) fazer a avaliaçáo da biometria testicular, visando identificar características gonadais de caititus adultos cativos, (ii) testar a eficiência da eletroejaculação para obtenção de sêmen de caititus, (iii) avaliar suas características seminais ao longo do ano, a fim de verificar sazonalidade quanto à produção e qualidade seminal de caititus mantidos em cativeiro e (iv) avaliar as características seminais quanto ao potencial para conservação e inseminação artificial. A partir da caracterização do sêmen de caititus mantidos em cativeiro, poderấo ser aplicadas técnicas de criopreservação seminal para viabilizar futuramente o estabelecimento de programas de reprodução assistida, úteis tanto para o melhoramento genético quanto para a construçấo de bancos de germoplasma para a conservação da espécie.

\section{MATERIAL E MÉTODOS}

\section{Local, Animais e Período Experimental}

O experimento foi realizado no Criatório Científico da Embrapa Amazônia Oriental, em Belém-PA (1²8' S

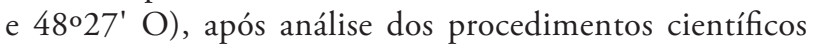
adotados e aprovaçáo pelo Comitê Técnico Interno da Embrapa. Oito caititus adultos (76,8 $\pm 37,8$ meses e $19,5 \pm$ $2,7 \mathrm{~kg}$ ) foram usados. Os animais foram alojados em baias coletivas, sendo alimentados com raçáo para suínos, frutos, forrageiras e água ad libitum. Vinte e quatro horas antes dos procedimentos experimentais, cada animal foi alojado em baia individual, permanecendo em jejum hídrico e alimentar por 12 horas. O experimento foi desenvolvido de outubro/2007 a fevereiro/2009, sendo que a freqüência de colheita por animal foi quinzenal.

\section{Sedação e Biometria Testicular}

Para sedaçáo e analgesia adequadas, foi usada associaçáo de acepromazina ( $0,2 \mathrm{mg} \mathrm{kg}^{-1}$ I.M., Acepran 0,2\% ${ }^{\circ}$, Univet S.A., São Paulo-SP) e quetamina ( $5,0 \mathrm{mg} \mathrm{kg}^{-1}$ I.M., Dopalen ${ }^{\circ}$, Vetbrands Saúde Animal, Jacareí-SP, Brasil), conforme descrito por Kahwage et al. (2008). Os procedimentos de biometria testicular e colheita seminal se processaram com os animais em decúbito lateral.

Para realizar a biometria testicular, os testículos foram levemente tracionados e posicionados paralelamente. Por palpação, foi avaliada a consistência testicular (escala de 0/ flácida a 5/firme) e os testículos direito e esquerdo de cada animal foram mensurados antes de cada colheita, com auxílio de um paquímetro manual graduado. Para aferir o comprimento, foram considerados somente os testículos, isolados da cauda e cabeça do epidídimo, enquanto a largura foi medida a partir da porção medial até a porção livre de cada gônada, conforme técnica descrita por Johnston et al. (1994).

\section{Colheita de Sêmen}

Previamente às sessóes de colheita seminal, foram realizadas limpeza cautelosa do reto, higienizaçáo externa e interna do prepúcio com soluçấo fisiológica pré-aquecida $\left(\mathrm{NaCl} 0,9 \%\right.$ a $\left.35{ }^{\circ} \mathrm{C}\right)$. As colheitas foram feitas com equipamento para eletroestimulação (Boijektor 2001 ${ }^{\circ}$, 
Comercial Barbôs Ltda., São Paulo-SP, Brasil), contendo um eletrodo retal desenvolvido especialmente pela equipe de pesquisa, segundo as características anatômicas de machos adultos da espécie $(20 \mathrm{~cm}$ de comprimento x $1,9 \mathrm{~cm}$ de diâmetro; três tiras longitudinais paralelas). $\mathrm{O}$ protocolo de estimulação adotado se baseou na aplicação de $45 \pm 13$ estímulos seguidos (12 volts, 3 segundos por estímulo), até que se iniciasse a liberação da fração em gel do ejaculado. Para avaliar a eficiência da eletroejaculação, durante todo o período experimental foram realizadas 117 tentativas de colheitas. A taxa de sucesso foi determinada pela quantidade de amostras contendo espermatozóides, em relação ao número total de tentativas de colheita.

\section{Avaliação Seminal}

$\mathrm{O}$ sêmen foi mantido em banho-maria a $35^{\circ} \mathrm{C}$, durante todo processo de análise. Primeiramente, foi realizada a avaliação visual do aspecto do ejaculado, representada por aparência e cor. Posteriormente, foi feita a determinaçáo do volume total $(\mathrm{mL})$. Caso houvesse a presença de gel, o mesmo era separado e pesado em balança analítica $(\mathrm{mg})$. Foi, então, aferido o volume ejaculado livre de gel.

Em seguida, foram avaliados sob microscopia a motilidade (\%) e o vigor (0-5) espermáticos, a partir de uma alíquota de $10 \mu \mathrm{l}$ de sêmen in natura. $\mathrm{O} \mathrm{pH}$ seminal foi determinado $(\mathrm{pH}$ Tests ${ }^{\circledR}$, Merck KGaA, Darmstadt, Alemanha). Para a obtenção da concentraçáo espermática, as amostras foram avaliadas em câmara hematimétrica, sendo o resultado expresso em milhóes de espermatozóides por mililitro (sptz $\left.\mathrm{mL}^{-1}\right)$.

Para a determinação da integridade da membrana plasmática, foi realizado esfregaço seminal, corado por eosina-nigrosina, a qual é uma coloração do tipo supravital (Galloway 1974). Foram contadas 200 células por amostra, sendo identificada a porcentagem de células com membrana plasmática intacta (MPI). A avaliação de morfologia espermática foi realizada em lâmina corada por vermelhocongo sob aumento de 1000 vezes, para detectar células com anormalidades (Hancock 1957). Foi feita a contagem de 200 células por amostra, com classificação individual das anormalidades, que foram agrupadas em defeitos maiores (patologias espermáticas ocorridas durante o processo de espermatogênese) e menores (defeitos espermáticos ocorridos durante o processo de maturação, armazenamento e trânsito dos espermatozóides no epidídimo), sendo os resultados apresentados em porcentagem, conforme descrito por Blom (1950).

\section{Análise Estatística}

As características seminais de volume, $\mathrm{pH}$, concentração, motilidade, vigor, integridade de membrana plasmática, defeitos maiores e defeitos menores foram analisadas estatisticamente, com auxílio do programa Biostat 5.0
(Ayres et al 2007). Para verificar o grau de associaçáo entre variáveis, foi aplicado o teste de correlaçáo de Pearson, com uso do programa NTIA versão 4.2.1 (Embrapa 1997), sendo considerados os valores do coeficiente de correlação acima de 0,5 , e estatisticamente significante quando $\mathrm{P}<0,001$.

\section{RESULTADOS E DISCUSSÃO}

\section{Biometria Testicular}

Os resultados de biometria testicular estáo sumariados na Tabela 1. Não foi detectada assimetria entre as gônadas esquerda e direita, corroborando os achados de Sonner et al. (2004). A consistência observada, de valor intermediário, correspondeu ao padrão fibro-elástico, semelhante ao encontrado em suínos e descrita como ideal para machos em reproduçâo. Os dados morfométricos foram ligeiramente inferiores aos observados na literatura, com descriçóes de comprimentos entre 4,2 a 4,9 cm e largura de 2,7 a 2,8 (Sonner et al. 2004; Carvalhal et al. 2000; Hellgren et al. 1989).

Tabela 1- Médias ( $\pm \mathrm{DP}$ ) dos parâmetros testiculares de animais adultos da espécie Tayassu tajacu criados em cativeiro. Belém-PA, 2009.

\begin{tabular}{lcc}
\hline Parâmetros Testiculares & Testículo Esquerdo & Testículo Direito \\
\hline Comprimento $(\mathrm{cm})$ & $3,8 \pm 0,4$ & $3,8 \pm 0,5$ \\
Largura $(\mathrm{cm})$ & $2,6 \pm 0,3$ & $2,6 \pm 0,3$ \\
Consistência $(0-5)$ & $2,3 \pm 0,2$ & $2,3 \pm 0,2$ \\
\hline
\end{tabular}

$P>0,05$

As correlaçóes entre os parâmetros avaliados podem ser observadas na Tabela 2. Verificou-se correlação significativa entre os comprimentos, as larguras e as consistências dos testículos direito e esquerdo. Esses resultados estão de acordo com os observados por Filgueira et al. (2005), que constataram alta correlação entre comprimento $(\mathrm{r}=0,7404)$ e circunferência $(r=0,9097)$ de testículos direito e esquerdo em caititus.

A correlação positiva entre comprimento, largura e consistência era esperada, uma vez que os testículos são órgãos pares e não há grandes diferenças encontradas entre eles, caso a organogênese tenha se processado normalmente (Sonner et al. 2004) e não tenham ocorrido patologias como monorquidismo, criptorquidismo ou hipoplasia (Nascimento e Santos 2003). Além disso, o desenvolvimento fisiológico das gônadas ocorre de modo equivalente nos dois eixos do órgão, preservando o formato testicular fusiforme e estabelecendo a simetria testicular, que interfere positivamente na atividade espermatogênica, fator considerado imprescindível para reprodutores. 
Tabela 2 - Correlações entre medidas testiculares e peso de Tayassu tajacu criados em cativeiro. Belém-PA, 2009.

\begin{tabular}{lcc}
\hline Variáveis & $r$ & $P$ \\
\hline Comp TE x Larg TE & 0,609 & $<0,001$ \\
Comp TE x Comp TD & 0,952 & $<0,001$ \\
\hline Comp TE x Larg TD & 0,637 & $<0,001$ \\
\hline Larg TE x Larg TD & 0,796 & $<0,001$ \\
Cons TE x Cons TD & 0,943 & $<0,001$ \\
Comp TD x Larg TD & 0,700 & $<0,001$ \\
\hline Peso x Comp TE & 0,676 & $<0,001$ \\
\hline Peso x Larg TE & 0,647 & $<0,001$ \\
Peso x Comp TD & 0,681 & $<0,001$ \\
Peso x Larg TD & 0,630 & $<0,001$ \\
\hline
\end{tabular}

Comp = comprimento $(\mathrm{cm}) ; \mathrm{Larg}=$ largura $(\mathrm{cm}) ; \mathrm{TD}=$ testículo direito; $\mathrm{TE}=$ testículo esquerdo; Peso $=$ peso vivo $(\mathrm{kg})$.

As correlaçôes entre peso e comprimento, e entre peso e largura testiculares apresentaram média intensidade, apesar de significantes. Isso indica que a variação de peso corpóreo pouco influenciou as dimensôes gonadais dos animais avaliados durante o período experimental. Possivelmente, o quadro observado ocorreu em função dos animais experimentais serem adultos e apresentarem estabilidade com relaçáo ao desenvolvimento corpóreo.

\section{Eficiência da Eletroejaculação}

Houve sucesso em 75,21\% (88/117) das tentativas de colheita de sêmen. Em 9,4\% das amostras colhidas, houve contaminação por urina e estas foram descartadas. Esse resultado é mais elevado que o encontrado por Morato et al. (1998), os quais observaram 3,7\% de amostras seminais contaminadas com urina em onças (Panthera onca), após uso da eletroejaculaçáo. No entanto, Busso et al. (2004), ao utilizarem a técnica em chinchilas (Chinchilla lanigera), obtiveram amostras seminais totalmente livres de urina em animais anestesiados. A causa da contaminação por urina pode estar relacionada ao posicionamento mais cranial do eletrodo, já que a inervação controladora da micção está muito próxima à inervação controladora da ejaculação, e o aprofundamento do eletrodo no momento da ejaculaçáo pode ocasionar a micção (Martin 1978).

A retenção do ejaculado no prepúcio ocorreu em 10,25\% das tentativas. Isto se deve à anatomia da genitália externa do caititu, pois a porção final do prepúcio forma uma espécie de divertículo com pequeno orifício. Este, associado ao formato em espiral da glande peniana, ocasiona o enrolamento da mesma e a contenção do pênis, favorecendo a ejaculação dentro da bainha prepucial. Portanto, para obter sucesso nas colheitas em caititus, há necessidade de fixação peniana logo após a ereção e exposição da glande.
Dos $24,79 \%$ de insucesso, $20,52 \%$ (24 repetiçôes) foi atribuído ao fato dos animais não terem ejaculado, resultado semelhante ao observado por Moreira et al. (2005), que ao testarem este método em queixadas (Tayassu peccari), obtiveram amostra seminal somente em $50 \%$ dos animais estudados. Esse resultado pode estar associado a uma resistência individual à estimulação por corrente elétrica (Haron et al. 2000), à insuficiente estimulaçấo elétrica aos órgáos do aparelho reprodutor (Rodger e Pollitt 1981) ou ao indevido posicionamento do eletrodo no assoalho pélvico.

Em 3,42\% das tentativas de colheita foi obtida somente a fração em gel, o que pode ser atribuído ao posicionamento mais caudal do eletrodo e estímulo somente das glândulas bulbouretrais. Souza et al. (2009) citam que a obtenção somente da fração gel sugere ejaculação incompleta. Em apenas uma amostra $(0,85 \%)$ houve a colheita somente de líquido seminal, resultado semelhante ao observado por Giuliano et al. (2007), que observaram azoospermia em 1,8\% das amostras seminais obtidas de lhamas (Lama glama).

\section{Características Seminais}

As avaliaçóes demonstraram que o sêmen de caititus pode ser dividido em três fraçôes: uma pobre (constituída de secreção das glândulas acessórias e pobre em células), uma rica e uma fração gel. Esses resultados estáo de acordo com os achados de Lochmiller et al. (1985), Hellgren et al. (1989) e Costa e Paula (2005). No entanto, nem todos os ejaculados tinham as três fraçôes. A maioria dos ejaculados (50 amostras=76,93\%) teve aspecto ralo, de cor esbranquiçada, caracterizando baixa concentração espermática, com até $200 \times 10^{6} \mathrm{sptz} \mathrm{mL}^{-1}$. No entanto, um pequeno número de amostras $(15$ amostras $=$ $23,07 \%$ ) teve aspecto leitoso e cor branca, com variaçáo de concentração de $217,7 \times 10^{6}$ a $647,5 \times 10^{6} \mathrm{sptz} \mathrm{mL}^{-1}$, o que está associado com alta celularidade. As características seminais observadas durante o período experimental estão apresentadas na Tabela 3.

Tabela 3 - Características seminais da espécie Tayassu tajacu obtidas por eletroejaculação (65 amostras). Belém-PA, 2009.

\begin{tabular}{lcccc}
\hline Variáveis & Média $\pm \mathrm{DP}$ & Mínimo & Máximo & Amplitude \\
\hline Vol. (mL) & $0,8 \pm 0,8$ & 0,1 & 5,0 & 4,9 \\
Conc. (x10 ${\text { sptz } \mathrm{mL}^{-1} \text { ) }}^{138,1 \pm 154,0}$ & 2,3 & 647,5 & 645,2 \\
pH (0-14) & $7,92 \pm 0,73$ & 7,0 & 9,0 & 2,0 \\
Motilidade (\%) & $52,8 \pm 29,1$ & 0 & 90,0 & 90,0 \\
Vigor (0-5) & $2,1 \pm 0,8$ & 0 & 3,0 & 3,0 \\
MPI (\%) & $55,4 \pm 28,6$ & 0 & 94,0 & 94,0 \\
Defeitos Maiores (\%) & $22,6 \pm 13,1$ & 4,5 & 57,0 & 52,5 \\
Defeitos Menores (\%) & $9,6 \pm 7,2$ & 1,0 & 30,0 & 29,0 \\
\hline Defeitos Totais (\%) & $31,9 \pm 13,5$ & 10,5 & 70,5 & 60,0 \\
\hline
\end{tabular}

MPI = espermatozóides com membrana plasmática intacta. 
O volume médio encontrado foi de $0,8 \pm 0,8 \mathrm{~mL}$, menor que os volumes de $1,3 \pm 1,1 \mathrm{~mL}$ verificados por Lochmiller et al. (1985), de 1,1 $\pm 0,1 \mathrm{~mL}$ observado por Hellgren et al. (1989), e de 3,11 $\pm 0,9 \mathrm{~mL}$ detectado por Costa e Paula (2005). Uma vez que a periodicidade ideal para colheitas na espécie ainda não foi definida, a freqüência quinzenal pode estar associada ao volume encontrado. Ademais, a experiência do operador pode gerar ejaculados com volumes variados. Segundo Vera Cruz (1959), ejaculados de suínos domésticos colhidos com auxílio de eletroejaculadores são caracterizados por um pequeno volume de gel $(<5,0 \mathrm{~mL})$ e um baixo volume de líquido seminal.

A concentração espermática média encontrada foi de $138,1 \pm 154,1 \times 10^{6} \mathrm{sptz} \mathrm{mL}^{-1}$, distinta dos relatos de Lochmiller et al. (1985) e Costa e Paula (2005), que observaram $354 \pm 173 \times 10^{6} \mathrm{sptz} \mathrm{mL}^{-1}$ e $87,0 \pm 53,1 \times 10^{6} \mathrm{sptz}$ $\mathrm{mL}^{-1}$, respectivamente. A concentraçáo média encontrada foi menor que $100 \times 10^{6} \mathrm{sptz} \mathrm{mL}^{-1} \mathrm{em} 32$ amostras (49,23\%), o que pode também estar relacionado com o método de colheita utilizado, pois a eletroejaculação possibilita maior estimulação das glândulas acessórias e obtenção de maior volume e menor concentração, possíveis cópulas pregressas e status social do animal estudado (Hellgren et al. 1989). No entanto, houve ejaculados que apresentaram celularidade muito maior à média obtida $\left(647,5 \times 10^{6} \mathrm{sptz} \mathrm{mL}^{-1}\right)$. Assim, presume-se que a concentração seminal fisiológica de caititus adultos pode variar e ser dependente, também, de fatores individuais.

A motilidade espermática média observada foi de 52,8 \pm $29,1 \%$, sendo mais elevada que os achados de Lochmiller $e t$ al. (1985), que encontraram 49,5 $\pm 15,8 \%$ e Costa e Paula (2005), que detectaram motilidade de $48,7 \pm 31,5 \% \mathrm{em}$ caititus. Já Souza et al. (2009) encontraram $85 \pm 8,0 \%$ de motilidade. $\mathrm{O}$ vigor médio observado no presente estudo foi de 2,1 $\pm 0,8$, similar ao encontrado por Costa e Paula (2005), que verificaram vigor de $2,1 \pm 1,4$.

A média de espermatozóides MPI encontrada foi de 55,4 \pm $28,6 \%$, valor menor que os relatados por Souza et al. (2009), que encontraram variaçáo de $74,3 \pm 35$ a $83,9 \pm 7,0 \%$ em caititus. A integridade de membrana plasmática também foi menor que o índice de 93\% observado por Evans e Ko (1990) em porcos miniatura, e dos relatados por Fischman et al. (2003), que avaliaram observaram $84 \pm 10 \%$ de células MPI em javalis. $\mathrm{O}$ pH médio seminal foi de 7,92 $\pm 0,73$, diferentemente do relatado por Costa e Paula (2005), que observaram variaçóes de $6,2 \pm 0,2$ a 7,6 $\pm 0,1$, mas semelhante a Souza et al. (2009), que verificaram pH entre 7,7 $\pm 0,5$ a $8,1 \pm 0,4$ em caititus adultos.

A média de defeitos maiores encontrada foi de 22,6 \pm 13,1\%, mais elevada que os achados de Lochmiller $e t$ al. (1985), que detectaram apenas 7,27,2 $\pm 5,9 \%$ em caititus.
No entanto, esses autores detectaram elevado número de defeitos menores $(64,4 \pm 15,2 \%)$, estando em desacordo com a média encontrada no presente estudo, que foi de 9,11 $\pm 5,8 \%$. A média de defeitos totais encontrada foi de 31,9 $\pm 13,5 \%$, menor que a média encontrada por Costa e Paula (2005) que observaram variação de defeitos totais entre 15,5 $\pm 2,4 \%$ e $55,5 \pm 16,1 \%$ em caititus adultos. Já Mollineau et al. (2007), ao avaliarem sêmen de cutias (Dasyprocta leporina), verificaram $35,14 \pm 2,7 \%$ de anormalidades totais. Segundo Mies Filho (1987), animais silvestres mantidos em cativeiro podem ter elevadas porcentagens de células morfologicamente anormais, se comparadas às espécies domésticas. Essa taxa elevada pode estar associada ao regime de cativeiro e constante estresse aos quais os animais são submetidos.

Os defeitos espermáticos maiores mais freqüentemente observados foram cauda fortemente dobrada ou enrolada $(9,9 \pm 12,0 \%)$, defeitos de acrossoma $(5,1 \pm 5,7 \%)$ e gota protoplasmática proximal $(4,2 \pm 4,2 \%)$. Os defeitos menores mais freqüentes foram gota protoplasmática distal $(5,5 \pm$ $6,8 \%)$ e inserção abaxial $(1,4 \pm 1,9 \%)$.

As correlaçôes observadas entre as características seminais estâo indicadas na Tabela 4. Foram identificadas relaçôes significativas entre motilidade espermática e vigor, motilidade e células MPI, e entre vigor e células MPI. A íntima relação entre a motilidade progressiva, vigor e porcentagem de células MPI estabelece maior acurácia no julgamento da integridade de membrana e efetiva aplicabilidade do ejaculado. Esses parâmetros são fortes indicadores que denotam a capacidade de movimentação celular, integridade de membrana e atividade metabólica, os quais estáo relacionados à fertilidade, uma vez que baixas motilidades espermáticas refletem negativamente na fertilização e na taxa de concepção (Britt et al. 1999).

Tabela 4 - Correlações entre as características seminais de Tayassu tajacu criados em cativeiro. Belém-PA, 2009.

\begin{tabular}{lcc}
\hline Variáveis & $r$ & $P$ \\
\hline Motilidade x Vigor & 0,820 & 0,001 \\
Motilidade x MPI & 0,983 & 0,001 \\
\hline Motilidade x Defeitos Maiores & $-0,644$ & 0,001 \\
Vigor x MPI & 0,802 & 0,001 \\
\hline Vigor x Defeitos Totais & $-0,832$ & 0,001 \\
MPI x Defeitos Maiores & $-0,652$ & 0,001 \\
\hline Defeitos Maiores x Defeitos Totais & 0,877 & 0,001 \\
\hline
\end{tabular}

MPI = espermatozóides com membrana plasmática intacta. 
Vale ressaltar a correlação negativa significativa observada entre motilidade e defeitos maiores, indicando que os defeitos maiores encontrados mais freqüentemente no sêmen de caititus estáo relacionados à cauda e/ou à peça intermediária, podendo interferir diretamente na capacidade de movimentaçáo celular e, conseqüentemente, na motilidade espermática progressiva.

\section{Perfil Seminal ao Longo do Ano}

Foi possível observar flutuações nos parâmetros seminais dos ejaculados ao longo do ano. Foram observados menores valores para os parâmetros seminais, principalmente entre março e maio, com reduçáo da motilidade e integridade de membrana plasmática (Figura 1), e concomitante aumento no total de defeitos espermáticos (Figura 2). Nesse período, a motilidade espermática média foi de $40,1 \pm 4,0 \%$, o vigor médio foi de $2,0 \pm 0,0$, a MPI média foi de $41,9 \pm 3,3 \%$, a média de defeitos maiores foi de $27,4 \pm 7,7 \%$, a média de defeitos menores foi de $11,2 \pm 1,7 \%$ e de defeitos totais foi de $38,5 \pm 9 \%$.

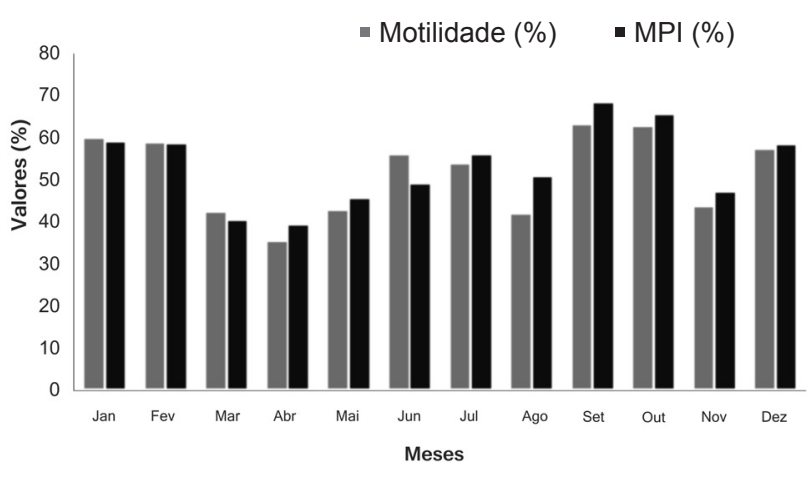

Figura 1 - Perfil da motilidade espermática e de espermatozóides com membrana plasmática intacta (MPI) de Tayassu tajacu mantidos em cativeiro.

A redução nos parâmetros seminais pode ter ocorrido em função de fatores ambientais (temperatura, umidade relativa do ar, luminosidade, estresse, precipitação pluvial), nutricional e fatores intrínsecos ao indivíduo (repouso sexual, enfermidades, comportamento, entre outros), os quais podem interferir na atividade reprodutiva, produção e qualidade seminal. A queda na qualidade seminal foi observada em todos os indivíduos estudados, independentemente do status social do animal.

Por outro lado, entre os meses de setembro e outubro, houve melhora na qualidade espermática, uma vez que a motilidade média verificada foi de $63,0 \pm 0,3 \%$, o vigor médio foi de 2,0 $\pm 0,0$, a média de células viáveis foi de $67,1 \pm 2,0 \%$, a média de defeitos maiores foi de 20,6 \pm $0,5 \%$, a média de defeitos menores foi de $9,6 \pm 4,7 \%$ e os defeitos totais médios foram de $29,4 \pm 5,02 \%$. Um estudo desenvolvido sobre eficiência reprodutiva por Mayor et al.

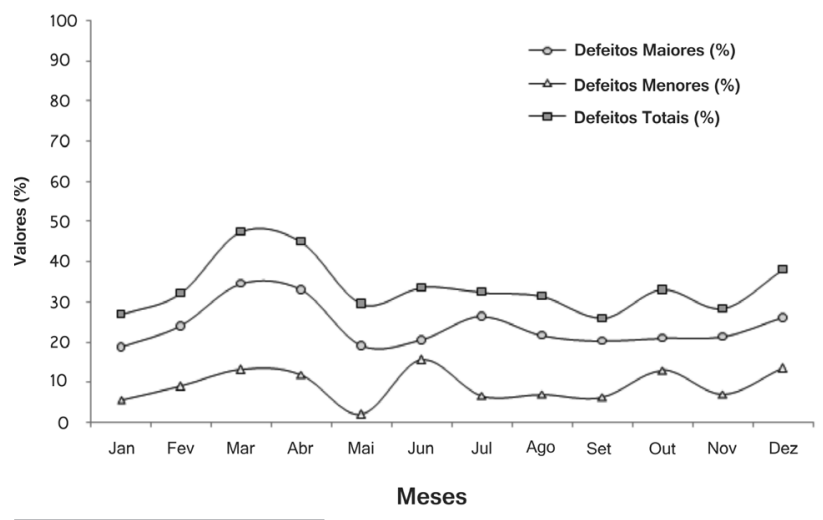

Figura 2 - Variação mensal de defeitos maiores, defeitos menores e defeitos totais em sêmen de Tayassu tajacu mantidos em cativeiro.

(2007) no mesmo criatório constatou que a concentração dos partos de caititus ocorre entre os meses de janeiro e março. Considerando que o tempo de gestaçáo em caititus é de, em média, 138 dias, supóe-se que o maior número de gestaçóes se inicie entre os meses de setembro e outubro, período que coincide com os meses de melhor qualidade seminal observados.

Durante o ano, as médias de motilidade variaram de $35,5 \%$ a $63,3 \%$, o vigor variou de 1,7 a 2,6, a MPI variou de $39,5 \%$ a $68,6 \%$. A variação para defeitos maiores, menores e totais foi de $18,7 \%$ a $34,5 \%, 5,6 \%$ a $15,6 \%$ e $27,0 \%$ a $47,5 \%$, respectivamente. Com base nos resultados observados, não é possível afirmar que as mudanças ambientais tiveram magnitude suficiente a ponto de indicar sazonalidade na produção seminal de caititus mantidos em cativeiro. Esses resultados corroboram os achados de Hellgren et al. (1989), que, ao avaliarem sazonalidade em animais de cativeiro, concluíram que o caititu macho adulto pode ser fértil o ano todo, mesmo que haja diminuição das concentraçôes de testosterona sérica durante o verão.

Considerando que o caititu é uma espécie silvestre sobre a qual há escassos estudos de fisiologia reprodutiva e que os animais utilizados náo foram previamente selecionados para fertilidade, os resultados médios de motilidade $(52,8$ $\pm 29,1 \%)$, integridade de membrana plasmática $(55,4$ $\pm 28,6 \%)$ e defeitos espermáticos totais $(31,9 \pm 13,5 \%)$ em sêmen obtido por eletroejaculaçáo, em protocolo de colheita ainda em aperfeiçoamento, podem ser considerados indicadores favoráveis à potencial estocagem de sêmen da espécie. Assim, os resultados obtidos para sêmen in natura podem representar o primeiro passo para a conservaçáo e para o melhoramento de rebanhos, que podem vir a ser inseminados artificialmente com sêmen criopreservado no futuro. 


\section{CONCLUSÕES}

(i) A biometria testicular em caititus adultos é semelhante à relatada na literatura para animais criados na natureza, sendo pouco influenciada pelo peso corpóreo. (ii) A técnica da eletroejaculação consiste em método eficiente para obtenção de sêmen de caititus, quando associada ao protocolo anestésico adequado. (iii) Machos da espécie Tayassu tajacu sexualmente maduros produzem ejaculados com características que os permitem ser considerados como potencialmente férteis durante o ano todo, caracterizando-os como animais de reprodução não sazonal. (iv) $\mathrm{O}$ sêmen de caititus (Tayassu tajacu) obtido por eletroejaculação possui características seminais indicativas de fertilidade, com potencial para desenvolvimento de técnicas de reprodução assistida ou armazenamento.

\section{AGRADECIMENTOS}

Os autores agradecem à Embrapa (código 01.07.01.02.04.06), UFPA e CNPq (processo 474882/20063) pelo suporte financeiro, bem como a Dr. Raimundo Parente de Oliveira, pelo apoio nas análises estatísticas.

\section{BIBLIOGRAFIA CITADA}

Andrabi, S.M.H.; Maxwell, W.M.C. 2007. A review on reproductive biotechnologies for conservation of endangered mammalian species. Animal Reproduction Science, 99: 223-243.

Ayres, M.; Ayres Junior, M.; Ayres, D. L.; Santos, A. A. S. 2007. BioEstat 5.0: Statistical applications in biomedical sciences. Belém: Sociedade Civil Mamirauá; Brasília: Ministério da Ciência e Tecnologia; Belém: Imprensa Oficial do Estado do Pará, 324p (in Portuguese).

Bennett, E. L.; Robinson, J. G. 2000. Hunting for sustainability: the start of a synthesis, p. 499-519. In: Robinson, J. G.; Bennett, E. L. Hunting for sustainability in tropical forests. New York: Columbia University Press.

Blom, E. 1950. On the evaluation of bull semen with special reference to the employment for artificial insemination. Copenhaguen: Carl F. Mortensen. 223p.

Britt, J.H.; Almond, G.W.; Flowers, W.L. 1999. Diseases of the reproductive system, p. 712 In: Straw B, D'Allaire S, Mengeling W, Taylor D. (eds), Diseases of Swine, 8th ed. Blackwell Science Ltd, Ames, IA.

Busso, J.; Ponzio, M.; Chiaraviglio, M.; Fiol De Cunel, M.; Ruiz, R. 2004. Electroejaculation in the Chinchilla (Chinchilla lanigera): effects of anesthesia on seminal characteristics. Research in Veterinary Science, 78(1): 93-97.

Carvalhal, R.; Cagnoto, D.G.; Daniel, R.J. 2000. Morphological features of testes and spermatic cord peccary. Brazilian Journal of Morphology Science, 17, Suppl:178 (in Portuguese).

Costa, D.S.; Paula, T.A.R. 2005. Semen collection and evaluation of the collared peccary (Tayassu tajacu). Biota Neotropica, 5(2):
1-6. (http://www.biotaneotropica.org.br). Acesso: 1/11/06 (in Portuguese).

Costa, D.S.; Henry, M.; Paula, T.A.R. 2004. Spermatogenesis of collared peccary (Tayassu tajacu). Arquivo Brasileiro de Medicina Veterinária e Zootecnia, 56(1): 46-55 (in Portuguese).

Costa, D.S.; Silva, J.F.; Silveira, L.S. 2007. Morphometry of Leydig cells in the collared peccary (Tayassu tajacu). Brazilian Journal of Veterinary Research and Animal Science, 44(5): 384-389.

Embrapa. 1997. Centro Nacional de Pesquisa e Tecnologia e Informática na Agricultura. Environment NTIA Statistical Analysis Software, version 4.2.1:User's Manual, Statistical Tooling. Campinas (in Portuguese).

Evans, L.E.; Ko, J.C. 1990. Electroejaculation and artificial insemination in Vietnamese potbellied miniature pigs. Journal of the American Veterinary Medical Association, 197(10): 1366.

Filgueira, K.D.; Moura, C.E.B.; Batista, J.S.; Silva, S.M.M.S.; Oliveira, M.F.; Albuquerque, J.F.G.; Miglino, M.A. 2005. Biometrics and histopathological changes in testes of peccary (Tayassu tajacu) maintained in captivity in semi-arid northeast, Brazil. Brazilian Journal of Veterinary Research and Animal Science, 42(1): 19-25 (in Portuguese).

Fischman, M.L.; Suhevic, J.; Rivolta, M.A.; Cisale, H.O. 2003. Collection of wild boar semen by electroejaculation. The Veterinary Record, 153: 365-366.

Galloway, D.B. 1974. Introductory review; factors affecting fertility, p.2-23 In: Bulls. Course held at the University of Queensland Veterinary School, 18-22 February.

Giuliano, S.; Director, A.; Gambarotta, M.; Trasorras, V.; Miragaya, M. 2007. Collection method, season and individual variation on seminal characteristics in the llama (Llama glama). Animal Reproduction Science, 104: 354-358.

Hancock, J.L. 1957.The morphology of boar spermatozoa. Journal of the Royal Microscopical Society, 76: 84-97.

Haron, W.; Ming, Y.; Zainuddin, Z.Z. 2000. Evaluation of semen collected by electroejaculation from captive Lesser Malay Chevrotain (Tragulus javanicus). Journal of Zoo Wildlife Medicine, 31: 164-167.

Hellgren, E.C.; Lochmiller, R.L.; Amoss, M.S.J.R.; Seager, S.W.; Magyar, S. J.; Coscarelli, K.P.; Grant, W. E.1989. Seasonal variation in serum testosterone testicular measurements and semen characteristics in the collared peccary (Tayassu tajacu). Journal of Reproduction and Fertility, 85: 677-686.

Homma, A.K.O. 1992. The animal extraction in Amazonia: the case of an illegal economy. Belém: EMBRAPA-CPATU. 86p (in Portuguese).

IAP (Instituto Ambiental do Paraná). 2009. Red List of Threatened Fauna of Paraná.2009. (http://celepar7.pr.gov.br/livrovermelho/). Acesso: 22/07/09 (in Portuguese).

Johnston, L.A.; Armstrong, D.L.; Brown, J.L. 1994. Seasonal effects on seminal and endocrine traits in the captive snow leopard (Panthera uncia). Journal of Reproduction and Fertility, 102: 229-236. 
Kahwage, P.R.; Garcia, A.R.; Bartha, M.M.P.; Guimarães, D.A.A.; Luz-Ramos, R.; Dias, H.L.T.; Albuquerque, N.I.; Ohashi, O.M. 2008. Development of protocol for sedation and analgesia in peccaries (Tayassu tajacu) to collect semen by electroejaculation. Anais... 35० Congresso Nacional de Medicina Veterinária. Sociedade de Veterinária do Rio Grande do Sul. Gramado-RS. Online. 2008 (in Portuguese).

Lochmiller, R.L.; Hellgren, E.C.; Varner, L.W.; Greene, L.W.; Amoss, M.S.; Seager, S.W.J.; Grant, W.E. 1985.Physiological responses of the adult male collared peccary Tayasu tajacu (Tayassuidae), to severe dietary restriction. Comparative Biochemistry Physiologic, 82(1): 49-58.

Martin, I.C.A. 1978. The principles and practice of electroejaculation of mammals. Symposium of Zoological Society of London, 43: $127-52$.

Mayor, P.; Guimarães, D.A.A.; Le Pendu, I.; Da Silva, J.; Jori, F; López-Béjar, M. 2007. Reproductive performance of captive collared peccaries (Tayassu tajacu) in the eastern Amazon. Animal Reproduction Science, 102: 88-97.

Mies Filho, A.1987. Reproduction of animals. 6 ed. Porto Alegre: Sulina. v.1/2, 750p (in Portuguese).

Mollineau, W.M.; Adogwa, A.O.; Garcia, G.W. 2007. A preliminary technique for electro-ejaculation for agouti (Dasyprocta leporina). Animal Reproduction Science, 108(1-2): 92-97.

Morato, R.G.; Guimarães, M.A.V.B.; Nunes, A.L.V.; Carciofi, A.C.; Ferreira, F.; Barnabe, V.H.; Barnabe, R.C. 1998. Semen collection and evaluation in the jaguar (Panthera onca). Brazilian Journal of Veterinary Research and Animal Science, 35(4): 178-181 (in Portuguese).

Moreira, N.; Erdmann, R.H.; Delgado, L.E.S.; Pachaly, J.R.; Ciffomi, E.M.; Hatamoto, L.K. 2005. Semen collection and andrological evaluation in peccary (Tayassu peccary). Anais... IX Congresso e XIV Encontro da Associaçáo Brasileira de Veterinários de Animais Silvestres (ABRAVAS). Centro Universitário Rio Preto (UNIRP). São José do Rio Preto-SP, p.67 (in Portuguese)
Nascimento, E.F.; Santos, R.L. 2003. Pathology of reproduction of domestic animals. Rio de Janeiro: Guanabara Koogan. 137p (in Portuguese).

Passamani, M.; Mendes, S.L. 2007. Endangered species in Espirito Santo. Vitória: Instituto de Pesquisas da Mata Atlântica. 140p (in Portuguese).

Rodger, J.C.; Pollitt, C.C. 1981. Radiographic examination of electroejaculation in marsupials. Biology of Reproduction, 24: 1125-1134.

Sonner, J.B.; Miglino, M.A.; Santos, T.C.; Carvalhal, R.; Neto, A.C.A.; Moura, C.E.B.; Oliveira, M.F. 2004. Macroscopic and morphometric features of testes in collared peccary and lipped peccary. Biota Neotropica, 4(2): 1-12. (http://www. biotaneotropica.org.br/v4n2/pt/fullpaper?bn03004022004+pt) Acesso: 20/01/08 (in Portuguese).

Souza, A.L.P.; Castelo, T.S.; Queiroz, J.P.A.F.; Barros, I.O.; Paula, V.V.; Oliveira, M.F; Silva, A.R. 2009. Evaluation of anesthetic protocol for the collection of semen from captive collared peccaries (Tayassu tajacu) by electroejaculation. Animal Reproduction Science, 116(3): 370-375.

Vera Cruz, N.C. 1959. Artificial insemination in pigs. I Semen collection by electrical stimulation in boars. Phillip Agriculture, 43: 225-235.

Wilson, E. O. 1994. Diversity of life. São Paulo: Companhia das Letras. 447p (in Portuguese).

Recebido em 03/02/2010

Aceito em 30/04/2010 